\title{
Çocukluk Dönemi Habilitasyon Uygulamaları
}

Habilitation Interventions in Childhood

\author{
Meral HURi ${ }^{1}$, Filiz ASLAN ${ }^{2}$, Kübra SEYHAN ${ }^{3}$, Esra AKI ${ }^{4}$, Mintaze KEREM GÜNEL ${ }^{5}$ \\ ${ }_{2}^{1}$ Doç. Dr., Hacettepe Üniversitesi, Sağlık Bilimleri Fakültesi, Ergoterapi Bölümü, Ankara, Türkiye \\ ${ }^{2}$ Uzm., Hacettepe Üniversitesi, Sağlık Bilimleri Fakültesi, Odyoloji Bölümü, Ankara, Türkiye \\ ${ }^{3}$ Uzm. Fzt., Hacettepe Üniversitesi, Fizyoterapi ve Rehabilitasyon Fakültesi, Ankara, Türkiye \\ ${ }^{4}$ Prof. Dr., Hacettepe Üniversitesi, Sağlık Bilimleri Fakültesi, Ergoterapi Bölümü, Ankara, Türkiye \\ ${ }^{5}$ Prof. Dr., Hacettepe Üniversitesi, Fizyoterapi ve Rehabilitasyon Fakültesi, Ankara, Türkiye
}

\section{öz}

Çocukluk dönemi; tüm çocuklar için, deneyim öğrendiği ve yaşı ile uyumlu günlük yaşam aktivitelerine katılım yolu ile sosyal katılım becerilerinin geliştiği ve toplumun bir parçası olduklarını öğrendikleri önemli bir fırsat dönemidir. Bu nedenle, herhangi bir yapı ve fonksiyon bozukluğu ile aktivite ve katılım kısıtılığı gösteren çocukların; en üst seviye performans becerilerini ortaya çıkarmalarına yardımcı olabilecek multidipliner / interdipliner / transdisipliner rehabilitasyon müdahalelerine ve hizmetlere en erken dönemde ulaşabilmelerinin, çocukların toplumsal katılım becerilerinin geliştirilebilmesi için çok önemli olduğu bilinmektedir. Dezavantajı bir grup olarak tanımlanan gelişimsel riskler ile karşı karşıya kalan çocuklara yönelik habilitasyon anlayışı ve çalışmaları dünyada olduğu gibi ülkemizde de hızla gelişme göstermektedir. Bu derlemede, aktivite ve katılım kısıtılığı gösteren çocuklara yönelik yeni beceri gelişimi ile farklı performans alanlarında kapasitelerini geliştirerek toplumsal/sosyal katılımlarının sağlanmasını hedefleyen, farklı disiplinlerden profesyonellerin ekip olarak çalıştığı; çocuk merkezli, aile ve bakım verenler ile çocuğun içerisinde bulunduğu fiziksel, sosyal ve kurumsal çevresel faktörlerin farklı boyutları ile detaylı olarak ele alındığı, çocuklara yönelik habilitasyon uygulamalarının incelenmesi amaçlanmıştır.

Anahtar kelimeler: Çocuk; Engellilik; Habilitasyon; Rehabilitasyon

\section{ABSTRACT}

Childhood period is a vital learning opportunity period in which children learn by experiencing and developing age related skills, enhance social participation by participating in daily life and learn that they are a part of the community. That brings out the importance of providing children, who have a limitation in body functions and structure, activity or participation, with multidisciplinary / interdisciplinary / transdisciplinary rehabilitation interventions and services as early as possible to help them develop the highest level of performance skills. The concept of habilitation and studies for children facing developmental risks identified as a disadvantaged group are developing rapidly in our country as well as in the world. In this review, it is aimed to examine the practices in which professionals from different disciplines work as a team aiming to develop children's capacity in different performance areas and to ensure their social / social participation by developing new skills for children with activity and participation limitations. Also, this study aims to examine the client-centered habilitation practices in which physical, social and environmental factors that affect the family, the caregivers and the child are discussed comprehensively.

Keywords: Child; Disability; Habilitation; Rehabilitation 
DSÖ verilerine göre dünya nüfusunun $\% 15$ 'inin (yaklaşık 150 milyon çocuk) engelli olduğu ve bu çocukların büyük bir çoğunluğunun geç dönemde tespit edilebildiği ve ihtiyaç duydukları hizmetlere halen ulaşamadıkları bilinmektedir (DSÖ, 2015). Ülkemizdeki oranlar incelendiğinde TUIK 2014 yılında; çocukluk çağı engellilik oranının tüm nüfusun \%8.7'sini oluşturduğu belirtilmektedir. Buna karşın ülkemizde de engelli çocuklara sunulan hizmetlerinin yetersiz ve halen tam olarak çocuk merkezli bir anlayış ile verilemediği belirtilmektedir (Arca ve Saka 2019; TUIK, 2014). Birleşmiş Milletler Çocuklara Yardım Fonu'nun ülkemizde engelli çocuklara yönelik sunulan hizmetlerin çoklu disiplinlerin verimli ve tam olarak ortak çalışmasına izin vermediğini, bireyselleştirilmiş eğitim programlarının halen iyi planlanmış işlevsel değerlendirme sonuçlarına göre hazırlanamadığını, bütüncül bir perspektif ile çocuk merkezli olarak planlanamadığını, aile/ bakım veren eğitimlerinin halen istenilen seviyeye çıkarılamadığını ve engelli çocuklara yönelik çevresel düzenlemelerin (ev, okul, park vb.) kısıtlı olduğunu belirtmektedir (WHO ve UNICEF, 2012). Bu nedenler çok boyutlu ve bu faktörlerden etkilenecek zayıf bir yapıya sahip olan dezavantajlı çocuk ve gençlere yönelik uygulanabilir, çok disiplinli, kişi, çevre ve aktivite merkezli, katıım odaklı, bütüncül müdahale yaklaşımlarının geliştirilmesi önemlidir (Guralnick, 2017). Bununla beraber çocuklar; sonradan edinilmiş engellilik, fonksiyon kayıpları olan erişkin bireylerden farklı olarak sahip oldukları yapı ve fonksiyon kayıpları, aktivite kısıtılıkları ve çevresel faktörlerden etkilendikleri için bir beceriyi ilk defa öğrenme deneyimi yaşamaktadırlar. Bu deneyim çocuğun sadece fizyolojik intiyaçlarının karşılanmasını hedefleyen geleneksel rehabilitasyon anlayışından ziyade nöral plastisite, motor öğrenme, aktivite adaptasyonu, aktivite performansı, günlük yaşam aktivitelerine katıım gibi farklı yaklaşımların da özenle irdelendiği aile ve bakım verenlerin ve hatta bireyin içerisinde yaşadığı toplumun üyelerinin de dahil edildiği farklı yaklaşımları benimsenmiş ve 1970-1980 yılları arasında ilk kez gündeme gelen "habilitasyon" kavramı olarak tanımlanmıştır (Crnic, Neece, McIntyre ve ark., 2017; Cook, Klein ve Chen, 2017). Bu kapsamda; bu derleme farklı rehabilitasyon yaklaşımlarının beraber kullanıldığı çocukluk çağı habilitasyon uygulamalarının ve rehabilitasyon terapistleri ve uzmanlarının habilitasyon uygulamalarındaki rol, görev ve sorumluluklarını gözden geçirebilmek amacı ile Hacettepe Üniversitesi Çocuk Habilitasyon ve
Uygulama Merkezi (CUHA) tarafından hazırlanmıştır.

\section{Habilitasyon Kavramı}

Rehabilitasyon ve habilitasyon aktivite kısıtılığı gösteren çocuklarının tam sosyal katılım gösterebilmeleri için kullanılan kavramlardır. Bu bağlamda rehabilitasyon kaza hastalık vb. herhangi bir neden ile kaybedilmiş bir becerinin yaşam becerilerinin yeniden kazandırılması için kullanılan yaklaşımlar ile bireyin var olan kapasitesi ile yeniden öğrenmesini ve normal olarak nitelendirilen kapasitesine yeniden ulaşabilmesi olarak tanımlanabilir. Latince "yapabilir duruma getirmek" anlamına gelen "habilitasyon" kavramı ise bireyin en üst seviye kapasite ve bağımsızlığa ulaşabilmesi için daha önceden bilmediği ve/veya kullanmadığı becerilerini geliştirmek olarak ifade edilmektedir (Aslan, 2017). Habilitasyon kavramının anlaşılması için en güzel örnek doğumdan itibaren çoğu gelişim alanlarında yaşıtlarından farklılık gösteren serebral palsi (SP)'li çocuklar verilebilir. Bu çocuklar daha önce hiç öğrenmedikleri/kazanmadıkları yeni becerileri kendi vücut yapı ve fonksiyonları, aktivite kısıtlıkları ve çevreleri dahilinde ilk kez öğrenecek ve bu beceriler yardımı ile günlük yaşam aktivitelerinde en üst seviye bağımsızlık seviyesine çıkarılmaya, yaşam kaliteleri arttırılmaya çalışılacaktır. Bu nedenle SP'li çocuklarda uygulanan müdahale yaklaşımı rehabilitasyon yaklaşımından ziyade bir habilitasyon yaklaşımı olarak tanımlanabilmektedir (Camden, Tétreault ve Swaine, 2010). Konu ile ilgili bir diğer örnek ise herhangi bir iş kazası nedeni ile mesleğini yapamaz duruma gelen bir çalışan için çalışanın eski mesleğini tekrardan yapabilir duruma gelmesi için yapılan kapasite geliştirme çalışmaları rehabilitasyon kavramı kapsamında incelenirken; bireye kaza sonrası arta kalan kapasiteleri doğrultusunda yapabileceği başka bir meslek öğretilmesi için kapasitesinin geliştirilmesi habilitasyon kavramı kapsamında incelenmektedir (Escorpizo, Brage, Homa ve ark., 2016).

Dünyada ve ülkemizde engellilik kavramındaki değişim ve gelişimin bireyin yapı ve fonksiyonlarına odaklanmaktan çok bireyin içerisinde yaşadığı çevresi ile etkileşimine odaklanılması gerekliliğinin farkına varılması ile gelişim göstermiştir. Bu gelişim sürecinde Bronfenberenner'in insan gelişiminin ekolojisi ve Samerff'un ekolojik ve sistem teorilerinin müdahale yaklaşımlarının oluşturulmasında etkili olduğu bilinmektedir. Bronfenbrenner'e göre insanın en iyi gelişimi içinde yaşadığı en yakın boyut olan mikrosisteminde meydana gelirken Sameroff'un 
dinamik sistem modelinde ise hem aileden etkilenen hem de aileyi etkileyen bir birey olarak tanımlanan çocuğun gelişimini en iyi şekilde tamamlayabilmesi için hem çocuğun hem de ailenin güçlendirilmesinin önemi vurgulanmaktadır (Bronfenbrenner, 1977; Sameroff, Seifer, Baldwin ve ark., 1977; Aslan, 2017).

Habilitasyon kavramı yeni bir kavram olmamakla birlikte; sıklıkla yerine rehabilitasyon kavramının kullanılması nedeni ile halen uygun anlamı ile kullanılamamaktadır. Son 50 yı içerisinde rehabilitasyon ve habilitasyon alanlarındaki ve anlayışındaki gelişmeler özellikle Avrupa ve Amerika'nın öncülük ettiği pediatrik rehabilitasyon gelenek ve yaklaşımlarının içinde habilitasyon kavramının daha etkin şekilde kullanılması ile sonuçlanmıştır (Aslan, 2017). Bununla beraber 2007'den beri habilitasyon ve rehabilitasyon hizmetleri sırasında bireyin güçlü ve zayıf yönlerinin çok disiplinli bir çerçevede mümkün olan en erken dönemde başlatılmasının önemi vurgulanmıştır. Bu süreçte özellikle insan haklarına verilen önemin gelişmiş bir şekilde ele alındığı dünya ülkelerinde öncelikli olmak üzere ve ülkemizde de habilitasyon hizmetleri uygulanmakta, bu hizmetlerin standartlarının ve kalitelerinin geliştirilmesi için düzenlemeler yapılmakta ve iyi uygulama örnekleri paylaşılmaktadır (Porter, 2016; Ekberg, Scarinci, Hickson ve ark., 2018).

\section{Habilitasyon Uygulamaları}

Sıklıkla çocukluklara yönelik planlanan müdahaleler için kullanılan habilitasyon; erişkin bireylere uygulanan müdahaleler ile benzerlik gösterse de çocukların erişkinin küçüğü olarak tanımlanamaz olması ve engelli çocukların da tipik gelişim gösteren yaşıtları ile eşit haklara sahip olduğu düşüncesi; çocukların fonksiyonel kapasitelerinin en üst düzeye çıkarılabilmesi için en erken dönemde başlatılmalıdır. Bazı ülkelerin ulusal düzenlemelerinde rehabilitasyon süreçlerinin sadece bireyin kaybettiği fonksiyonlarını yeniden kazanmaları ve yeniden çalışabilir hale getirilebilmelerinin öncülük ettiği bakış açısı, çocuk ve adölesanlarda doğum öncesi, doğum sırası ve doğum sonrasında herhangi bir neden ile karşı karşıya kalınan fonksiyon, aktivite ve katılım kısıtlılıklarının rehabilitasyon hizmeti kapsamına alınmalarını azaltabilmektedir (Aslan, 2017). Çocukluk dönemine ait habilitasyon iyi uygulama örneklerinin sıklıkla işitme ve görme kaybı olan, SP, otizm spektrum bozukluğu ve Down sendromu gibi toplum içerisinde görülme sıklığı daha yaygın olan durumlara yönelik verildiği ve bu uygulamaların sıklıkla konuya özel merkezler tarafından sunulduğu göze çarpmaktadır. Amerika, Almanya, Belçika, Çin, Danimarka, İsveç, Norveç içerisinde doktor, fizyoterapist, ergoterapist, dil ve konuşma terapisti, odyolog, klinik psikolog, özel eğitim uzmanı, sosyal hizmet uzmanı gibi farklı disiplinlerin ortak çalışmasına imkan sağlayan merkezlerin olduğu bilinmektedir. Habilitasyon merkezlerinin etkin olarak hizmet verdiği ülkelerde aileler çocukları ile ilgili herhangi bir konu hakkında yardım/destek almak istediklerinde herhangi bir çocuk sağlığı birimine başvurduklarında gerekli görülür ise habilitasyon merkezlerine yönlendirilmekte veya habilitasyon merkezlerinde görev alan her hangi bir profesyonele başvurulduğunda müdahale yönetimi hızlı şekilde ekip içerisinde şekillendirilmektedir (Bøttcher, Stadskleiv, Berntsen ve ark., 2016; Haglund, Dahlgren, Råstam ve ark., 2017).Yapılan araştırmalar doğrultusunda ülkemizde benzer uygulamalar olsa da tam anlamıyla habilitasyon konusunda hizmet veren kısıtlı sayıda merkez olması ve konu ile ilgili farkındalık çalışmalarının yanı sıra aktif müdahale yaklaşımlarına öncülük etmesiyle Hacettepe Üniversitesi Çocuk Habilitasyon Merkezi (CUHA) çalışmaları göze çarpmaktadır.

\section{Çocuğun Sağlığa Erişim Hakkının Bir Parçası Olarak Habilitasyon}

Günümüzde yeni doğan bebeklerin neredeyse \%10'u gelişimsel gerilikler ile karşı karşıya kalırken en az \%1'i şiddetli engel/çoklu engel durumları ile karşı karşıya kalmaktadır. Türkiye'de ve Birleşmiş Milletler Çocuk Hakları Sözleşmesi'nde de belirtildiği gibi 18 yaş altı bireyler çocuk olarak kabul edilmektedir. Ülkemizde engelli nüfusun toplam nüfus içindeki oranı \%12.29' dur. Aile ve Sosyal Politikalar Bakanlığı ile Türkiye İstatistik Kurumu (2010) tarafından yapılan özürlülerin sorun ve beklentileri araştırmasına göre ise 0-6 yaş grubundaki çocukların \%25.1'inin dil ve konuşma özürlü, \%9.6'sının işitme özürlü, \%7.4'ünün zihinsel özürlü, \%3.7'sinin ortopedik özürlü, \%3.7'sinin çoklu özürlü, \%3.6'sının süreğen hastalıklı, \%2'sinin ruhsal ve duygusal özürlü, \%1.4'ünün görme özürlü olduğu belirlenmiştir. Çocukların sağlık hizmetleri ile ilgili yasal düzenlemeler ülkemizin de kabul ettiği Birleşmiş Milletler Çocuk Haklarına İlişkin Sözleşme ve Birleşmiş Milletler Engellilerin Haklarına İlişkin Sözleşme ile belirtilmiştir. Türkiye, Çocuk Hakları Sözleşmesi'ni 1995'te uygulamaya başlamıştır. Birleşmiş Milletler Çocuk Hakları Sözleşmesine göre 
özellikle madde 6,23 , ve 24 çocukların sağlık, ve eğitim haklarını içermektedir ve rehabilitasyon hizmetlerini kapsamaktadır. Madde 25; engelli bireylerin sağlık hakları ve Madde 26; habilitasyon ve rehabilitasyon kavramlarını ve haklarını içerir (Birleşmiş Milletler, 2006).

Habilitasyon merkezleri kapsamında çocuğa ait vücut yapı ve fonksiyonlarındaki kayıp, aktivite ve katılım kısıtılıkları erken dönemde belirlenmeye çalışılmakta ve konuya ilişkin müdahale yaklaşımları ekip içerisinde planlanmaktadır. Bu kapsamda habilitasyon sürecinde yapılan tıbbi, eğitim ve psikososyal yaklaşımların yani çocuğun öncelikli olarak ilişkide olduğu ev, okul ve sosyal ortamların ve çocuğun bu ortamlardaki katılım seviyesinin değerlendirilmesi desteklenmelidir.

Ev düzenlemeleri ile çocuğun yeni beceriler kazanabilmesine ve kazandığı bu becerileri kullanarak geliştirebilmesine imkan sağlayacak şekilde veya okul/sınıf düzenlemeleri, öğretmenterapist-aile ilişkisinin yapılandırılması ve önceliklerin belirlenmesi ile beraber günlük yaşama ve toplumsal yaşama (gezme, alışveriş, parkta oynama, sinemeya gitme vb.) katılımının desteklenmesi örnek olarak verilebilir. Çocuğun yanı sıra ailenin de habilitasyon ekibi içerisinde terapi programının kısa ve uzun dönem terapi hedeflerinin belirlenmesi sürecine dahil edilmesi habilitasyonun bir diğer ana önemli konusudur (Tye-Murray, 2009).

Dünya Sağlık Örgütü'nün 2030 yılı için planlanan "Rehabilitasyon Hareketi için Çağrı"sında habilitasyonun bireylere ulaştırılması için sağlık hizmetleri çatısı altında yapılması önerilen uygulamalar içerisinde multidisipliner / interdispliner / transdisipliner habilitasyon müdahalelerinin bireyin intiyaçlarının değerlendirilerek uygulanması yer almaktadır (Novak ve Berry, 2014). Multidisipliner yaklaşımda, eğitimli ve alanında uzmanlaşmış profesyonellerin bulunması beklenir. Bu nedenle multidisipliner habilitasyon uygulamasında hem toplumun ihtiyaçlarının belirlenmesi hem de yüksek seviye mesleki yeterlilikleri olan farklı uzmanlık alanlarındaki profesyonellerin (doktor, çocuk gelişim uzmanı, dil ve konuşma terapisti, ergoterapist, fizyoterapist, odyolog, klinik psikolog, hemşire vb.) ortak çalışabiliyor olması önemli yer tutar. Her uzmanlık alanı farklı bakış açılarını kullanır. Sonunda gözlem açısı ve farklı disiplinlerden elde edilen sonuçlar bir araya getirilir ve aynı probleme tüm disiplinlerin kendi bakış açısıyla bakmasının sağlanması ana amaçtır. Multidisipliner yaklaşımın bir ileri aşaması olan interdisipliner yaklaşımda ise, farklı alanlardaki uzmanlar kendi klinik, kavramsal ve metodolojik kimliklerini yaratırlar. $\mathrm{Bu}$ sayede; ilgilenilen problem daha kapsamlı ve bütünleştirilerek değerlendirilmiş olur. Literatür çalışmaları habilitasyon uygulama ve hizmetlerinin sunumu için kısıtlı sayıda uzman ve/veya zaman karşısında transdisipliner yaklaşımın kullanılabileceği önerilmektedir. Bu yaklaşımda, teorilerin, yöntemlerin ve sistemlerin bir araya getirilmesi için yeni yolların geliştirilmesi çabası vardır. Böylece birden fazla disiplindeki teorilerin ve bakış açılarının bütünleştirilerek paylaşıldığı kavramsal bir çerçeve kullanılır. Dünyada ve ülkemizde yapılan çalışmalar dezavantajlı çocuğun ekip içerisinde multidisipliner, interdispliner ve/veya transdisipliner olarak ele alındığı müdahale yaklaşımlarının bireysel uygulamalardan daha başarılı olduğunu ortaya koymaktadır (Kesselring ve Oesch, 2017; Shemek, Carey, Ott ve ark., 2018)

Dünya'da olduğu gibi ülkemizde de her hastanın habilitasyon sürecinde yer alacak uzman sayısı yeterli olmadığı için birden fazla engeli olan ve birden fazla alanda engelli olarak adlandırılan çocuklar farklı kurumlardaki uzmanlar tarafından değerlendirilebilmektedirler. $\mathrm{Bu}$ nedenle sıklıkla uzmanlar kendi alanlarındaki terminolojileri kullanarak çocuğun yaşadığı problemi açıklamaktadır. Farklı terimlerin kullanılması uzmanlar arasındaki iletişimi olumsuz yönde etkileyebilir ve çocuğun kuvvetli ve zayıf yönleri/kısıtılıkları hakkında açık ve anlaşılır bilgi almasını engelleyebilir. Habilitasyon kavramının en önemli hedeflerinden biri, ortak dil kullanımı ile ortak amaçların belirlenmesidir. Bu yaklaşım etkin bir takım çalışmasının sağlanabilmesi için habilitasyon sürecinin önemli bir aşamasıdır. Ortak bir dilin kullanılması ile birlikte uzmanlar arasında iletişim gelişmekte ve farklı bakış açılarının katkısı artmaktadır. Diğer yandan ortak dilin kullanılması sayesinde ailenin ve çocuğun habilitasyon sürecine katılımı daha kolay olmaktadır. Günümüzde etkili habilitasyon yöntemi olarak kabul gören çocuğun ve ailesinin merkezde olduğu uygulamalar için de ortak dilin kullanılması kolaylaştırıcı olmaktadır. DSÖ, habilitasyon alanındaki bu eksiği gidermek amacıyla ICF'i yayınlamıştır. Böylece farklı alanlarda çalışan uzmanların ortak bir dilde iletişim kurabilmesi ve habilitasyon süreci için bütüncül bir bakış açısının sağlanması hedeflenmiştir (Harty, Griesel ve Van der Merwe, 2011).

Habilitasyon alanında yapılan çalışmaların etkililiğini göstermede tercih edilen yaklaşımlardan biri de ekonomik yaklaşımdır. Bu yaklaşıma göre müdahaleler sonrasında elde edilen kazanç 
matematiksel analizler sonrasında bir karar verme süreçleri, kazanç-etkililik veya doğrudan veya dolaylı yoldan açıdan müdahale programının çocuğun hayatındaki etkisi oranın belirlendiği fayda-harcama analizleri kullanılabilir. Habilitasyon alanında yapılan harcamaların topluma geri dönüşü açısından değerlendirildiğinde, maliyet analizi için ekonomistlerin bakış açılarından da yararlanılmaktadır. Bu açıdan çı̆̆ır açan çalışmalara, okul öncesi dönemde eğitime yapılan yatırımın ekonomik olarak en yüksek oranda geri dönüşü sağladığını gösterdiği çalışmasıyla Nobel alan James Heckmen katkı sağlamıştır. 2006 yılındaki makalesinde, dezavantajlı çocukların toplumsal ve ekonomik olarak desteklenmesinden sağlanan geri dönüşün yetişkinlik döneminde yapılan yatırımdan geri dönüşün ekonomik olarak daha fazla olduğunu belirtmektedir (Heckman, 2006). Erken müdahale ile ilgili çalışmalara yön veren isimlerden olan Shonkoff, özel gereksinimi olan çocuklara uygulanan erken müdahale programlarının etkililiğine vurgu yapan ilk uzmanlardandır (Shonkoff ve Hauser-Cram, 1987). Müdahale programlarında ebeveyni ve çocuğu da sürece dahil eden programların en başarılı sonuçları elde ettiğini bildirmektedir (King, Schwellnus, Servais ve ark., 2019).

\section{Sonuç}

Çocukluk dönemi geleceğin yetişkinleri için beceri kazanımı ve sosyal yaşama katılımı için önemli bir fırsat dönemidir. Bu durum normal gelişim gösteren çocuklar ile eşit haklara sahip herhangi bir neden ile vücut yapı ve fonksiyonlarında bir kayıp, aktivite ve katıım kısıtıılıkları ile karşı karşıya kalan tüm dezavantajlı çocuklar için de geçerlidir. Bu kapsamda çocukların yaşları ve becerileri ile uyumlu olarak fonksiyonlarını ve performans kapasitelerini geliştirmek, günlük yaşam aktivitelerine katılımlarını sağlayacak müdahale ve hizmetlere en erken dönemde ulaşmalarının sağlanması önemlidir. Çocukluk dönemine ait dezavantajlı durumlar; erişkinlik döneminden farklı bir çerçevede yer alan, oldukça hassas ve özel yaklaşımlar ile ele alınması gereken bir dönemdir. Habilitasyon yaklaşımı, dezavantajlı çocuğun yeni becerileri ilk kez deneyimleyerek öğrendiği fikri ile yapılan tüm uygulama, müdahale yaklaşımları ve hizmetleri içermektedir. Ülkemizde bu anlayış ve çocukluk dönemine özgü; çocuğun merkeze alındığı hekimin yanı sıra çocuk gelişim uzmanı, dil ve konuşma terapisti, fizyoterapist, ergoterapist, psikolog, hemşire, sosyal hizmet uzmanı gibi profesyonellerin ekip olarak çalıştığı yaklaşım gelişmekte ve çocukların farklı alanlardaki performans kapasitelerinin arttırılması ile toplumsal katılımlarının geliştirilmesine yönelik çalışmalar sürdürülmektedir. Bu kapsamda; çocuğun istekleri ile güçlü ve zayıf yönlerinin dikkate alındığı, aile ve bakım verenlerin sürece dahil edildiği, çocuğun içinde yaşadığı fiziksel, sosyal ve kurumsal çevrenin müdahale yaklaşımlar ile desteklendiği; ortak bir dil kullanılan, maliyet etkin, bütüncül habilitasyon yaklaşımlarının geliştirilmesi, bu alanda hizmet veren merkezlerin sayısının arttırılması ve iyi uygulama örneklerinin yaygınlaştırılmasının önemli olduğu düşünülmektedir.

\section{Kaynaklar}

Adolfsson, M. (2017). The ICF-CY in habilitation services for children. In S. Castro \& O. Palikara (Eds.), An Emerging Approach for Education and Care (First Edition, pp. 187203). UK: Routledge.

Aile ve Sosyal Politikalar Bakanlığı \& Türkiye İstatistik Kurumu (2010). Engellilerin sorun ve beklentileri araştırması. Erişim tarihi 27 Eylül 2019, https://biruni.tuik.gov.tr/yayin/zkau/view/z_eyx/IY0Qgm2/ 6f41/1/Dokuman.pdf

Alexander, M. A., Matthews, D. J., \& Murphy, K. P. (Eds.). (2015). Pediatric rehabilitation: Principles and practice (5th edition). New York, NY, USA: Demos Medical Publishing.

Arca, M., \& Saka, G. (2019). Engellilerin temel hizmetlere ulaşılabilirliği ve beklenti durumları. Euras J Fam Med, 8(2), 69-77. https://doi.org/10.33880/ejfm.2019080203

Aslan, F. (2017). Çocukluk dönemi engeliliğinde habilitasyon uygulamaları ve hemşirelerin rolleri. Sağlık Bilimleri ve Meslekleri Dergisi, 4(3), 260-266. https://doi.org/10.17681/hsp.282687

Bøttcher, L., Stadskleiv, K., Berntsen, T., Christensen, K., Korsfelt, Å., Kihlgren, M., \& et al. (2016). Systematic cognitive monitoring of children with cerebral palsy-The development of an assessment and follow-up protocol. Scand J Disabil Res, 18(4), 304-315. https://doi.org/10.1080/15017419.2015.1091035

Bronfenbrenner U. (1977). Toward an experimental ecology of human development. American Psychologist, 32(7), 513531. http://dx.doi.org/10.1037/0003-066X.32.7.513

Camden, C., Tétreault, S., \& Swaine, B. (2010). Rehabilitation for children-How is it different from rehabilitation for adults. In J. Stone \& M. Blouin (Eds.), International Encyclopedia of Rehabilitation, (First Edition, pp.104-108). USA: CIRRIE.

Carulla, L. S., Reed, G. M., Vaez Azızı, L. M., Cooper, S. A., Leal, R. M., Bertelli, M., \& et al. (2011). Intellectual developmental disorders: Towards a new name, definition and framework for "mental retardation/intellectual disability" in ICD-11. World Psychiatry, 10(3), 175-180.

Cook, R. E., Klein, M. D., \& Chen, D. (2015). Adapting early childhood curricula for children with special needs (9th 
edition). Essex, UK: Pearson.

Crnic, K. A., Neece, C. L., McIntyre, L. L., Blacher, J., \& Baker, B. L. (2017). Intellectual disability and developmental risk: Promoting intervention to improve child and family wellbeing. Child Dev, 88(2), 436-445. https://doi.org/10.1111/cdev.12740

Ekberg, K., Scarinci, N., Hickson, L., \& Meyer, C. (2018) Parent-directed commentaries during children's hearing habilitation appointments: A practice in family centred care. Int J Lang Comm Dis, 53(5), 929-946. https://doi.org/10.1111/1460-6984.12403

Escorpizo, R., Brage, S., Homa, D., \& Stucki, G. (2016) Handbook of Vocational Rehabilitation and Disability Evaluation: Application and Implementation of the ICF. USA: Springer.

Guralnick, M. J. (2017). Early intervention for children with intellectual disabilities: An update. J Appl Res Intellect Disabil, 30(2), 211-229. https://doi.org/10.1111/jar.12233

Haglund, N., Dahlgren, S., Råstam, M., Gustafsson, P., \& Källén, K. (2017). Improvement of autism symptoms after comprehensive intensive early interventions in a clinical setting. Eur Psychiatry, 41, S129. https://doi.org/10.1016/j.eurpsy.2017.01.1940

Harty, M., Griesel, M., \& Van der Merwe, A. (2011). The ICF as a common language for rehabilitation goal-setting: Comparing client and professional priorities. Health Qual Life Out, 9(1), 87. https://doi.org/10.1186/1477-7525-9-87

Heckman, J. J. (2006). Skill formation and the economics of investing in disadvantaged children. Science, 312(5782), 1900-1902.

Illum, N. O., Bonderup, M., \& Gradel, K. O. (2016) Environmental needs in childhood disability analysed by the WHO ICF, Child and Youth Version. Dan Med J, 63(6), $1-5$

Kesselring, J., \& Oesch, P. (2017). Teamwork in rehabilitationIt is effective but it must be financed. Swiss Med Wkly, 147(2526). https://doi.org/10.4414/smw.2017.14449

King, G., Schwellnus, H., Servais, M., \& Baldwin, P. (2019). Solution-focused coaching in pediatric rehabilitation: Investigating transformative experiences and outcomes for families. Phys Occup Ther Pedi, 39(1), 16-32. https://doi.org/10.1080/01942638.2017.1379457

Martin Ginis, K. A., Ma, J. K., Latimer-Cheung, A. E., \& Rimmer, J. H. (2016). A systematic review of review articles addressing factors related to physical activity participation among children and adults with physical disabilities. Health Psychol Rev, 10(4), 478-494. https://doi.org/10.1080/17437199.2016.1198240

Novak, I., \& Berry, J. (2014). Home program intervention effectiveness evidence. Phys Occup Ther Pediatr, 34(4), 384-389. https://doi.org/10.3109/01942638.2014.964020

Oliver, M. (2017). Defining impairment and disability: Issues at stake. In E.F. Emens \& M.A. Stein (Eds.), Disability and Quality Law (First Edition, pp. 3-18). UK: Routledge.

Porter, J. (2016). Time for justice: Safeguarding the rights of disabled children. Disability \& Society, 31(8), 997-1012. https://doi.org/10.1080/09687599.2016.1223605

Rimmer, J. H. (2017). Equity in active living for people with disabilities: Less talk and more action. Preventive Medicine, $\quad 95, \quad$ S154-S156. http://dx.doi.org/10.1016/j.ypmed.2016.12.037

Sameroff, A. J., Seifer, R., Baldwin, A., \& Baldwin, C. (1993). Stability of intelligence from preschool to adolescence:
The influence of social and family risk factors. Child Dev, 64(1), $\quad$ 80-97. https://doi.org/10.1111/j.14678624.1993.tb02896.x

Shemek, M., Carey, D. H., Ott, A., Tiedemann, A., Moffa, L., Stanzione, M., \& et al. (2018). Assessing the need for a multidisciplinary patient and family education pediatrics Inpatient rehabilitation setting. Erişim tarihi 27 Eylül 2019, https://sigma.nursingrepository.org/bitstream/handle/107 55/623917/Shemek_89881.pdf?sequence=1\&isAllowed= $\mathrm{y}$

Shonkoff, J. P., \& Hauser-Cram, P. (1987). Early intervention for disabled infants and their families: A quantitative analysis. Pediatrics, 80(5), 650-658.

Simeonsson, R. J., \& Lee, A. (2017). The international classification of functioning, disability and health-children and youth. In S. Castro \& O. Palikara (Eds.), An Emerging Approach for Education and Care: Implementing a Worldwide Classification of Functioning and Disability, (First Edition, pp. 22-29). USA: Routledge.

Tye-Murray, N. (2009). Foundations of aural rehabilitation: Children, adults, and their family members (3rd edition). Clifton Park, NY, USA: Delmar.

United Nations (2006). Convention on the Rights of Persons with Disabilities. Erişim tarihi 27 Eylül 2019, https://www.un.org/development/desa/disabilities/conven tion-on-the-rights-of-persons-with-disabilities.html

World Health Organization \& United Nations Children's Fund (UNICEF). (2012). Early Childhood Development and Disability: A Discussion Paper. Retrieved from the Web $\begin{array}{lll}\text { September } & 27 & 2019 \text {, }\end{array}$ https://apps.who.int/iris/bitstream/handle/10665/75355/9 789241504065_eng.pdf?sequence=1\&isAllowed=y

World Health Organization. (2015). WHO Global Disability Action Plan 2014-2021: Better Health for All People with Disability. Retrieved from the Web September 27, 2019. https://apps.who.int/iris/bitstream/handle/10665/199544/ 9789241509619_eng.pdf?sequence=1 